Article

\title{
Supercritical Assisted Production of Lutein-Loaded Liposomes and Modelling of Drug Release
}

\author{
Paolo Trucillo ${ }^{1,2, *(\mathbb{D})}$, Mathieu Martino ${ }^{3}$ and Ernesto Reverchon ${ }^{1}$ \\ 1 Department of Industrial Engineering, University of Salerno, Via Giovanni Paolo II, 132, 84084 Fisciano, Italy; \\ ereverchon@unisa.it \\ 2 Department of Chemical, Material and Industrial Production Engineering, University of Naples Federico II, \\ Piazzale V. Tecchio, 80, 80125 Napoli, Italy \\ 3 Aix Marseille, CNRS, Centrale Marseille, M2P2, 13451 Marseille, France; mathieu.martino@univ-amu.fr \\ * Correspondence: paolo.trucillo@unina.it; Tel.: +39-(329)-656-6043
}

check for updates

Citation: Trucillo, P.; Martino, M.; Reverchon, E. Supercritical Assisted Production of Lutein-Loaded Liposomes and Modelling of Drug Release. Processes 2021, 9, 1162. https://doi.org/10.3390/pr9071162

Academic Editor: Dimitrios

I. Gerogiorgis

Received: 31 May 2021

Accepted: 1 July 2021

Published: 4 July 2021

Publisher's Note: MDPI stays neutra with regard to jurisdictional claims in published maps and institutional affiliations.

Copyright: (c) 2021 by the authors. Licensee MDPI, Basel, Switzerland This article is an open access article distributed under the terms and conditions of the Creative Commons Attribution (CC BY) license (https:// creativecommons.org/licenses/by/ $4.0 /$ )

\begin{abstract}
In this work, a lipophilic ophthalmic drug, lutein, has been entrapped in liposomes, using a supercritical assisted process. Effects of pressure, temperature, and drug to lipid ratio variation were studied on mean diameters and lutein encapsulation efficiency. Liposomes with diameters between $153 \pm 38$ and $267 \pm 56 \mathrm{~nm}$ were produced, and lutein encapsulation efficiencies between $86.5 \pm 0.4 \%$ and $97.8 \pm 1.2 \%$ were obtained. A Scanning Electron Microscope confirmed spherical shape and mean dimensions of vesicles. The variation of temperature for the production of liposomes showed a significant impact on lutein retention time in the double lipidic layer. Lutein drug release from liposomes produced at $35^{\circ} \mathrm{C}$ ended in almost 4.5 days; whereas, liposomes produced at $40{ }^{\circ} \mathrm{C}$ showed a faster lutein release in 3 days; then, vesicles obtained at $45^{\circ} \mathrm{C}$ released their lutein content in only 2 days. Drug release raw data were well-fitted using Weibull model ( $R^{2}$ up to $99 \%$ ).
\end{abstract}

Keywords: liposomes; supercritical fluids; carbon dioxide; high pressure systems; antibiotics; lutein; drug delivery; Weibull model

\section{Introduction}

Drug delivery systems have been developed in different shapes and configurations to achieve one main goal: drug protection until reaching target cells [1]. This resulted in a significantly reduced drug loss, a most powerful targeted drug delivery, and a drastic reduction of the side effects [2].

Among drug carriers, liposomes are spherical particles characterized by an inner aqueous core and a lipidic external double layer [3]. These vesicles are particularly versatile, since they can entrap hydrophilic compounds in the inner core and lipophilic drugs in the double lipidic layer [4]. However, amphiphilic molecules can also be easily loaded, considering them as surfactants that cover the inner aqueous core [5]. Liposomes have been clearly recognized as the most used non-toxic drug carriers, since they are biocompatible with cell barriers and have the ability to fuse with them [6]. Moreover, due to their high biocompatibility and enhanced bioavailability of the loaded drugs, liposomes are considered the main key for the development and administration of a large number of drugs, such as antibiotics, proteins, dyes and markers, dietary supplements, and chromophores molecules; last but not least, liposomes are nowadays largely employed for the administration of vaccines, included the ones against COVID-19 disease [7].

Despite the importance of liposomes, which has been nowadays well-accepted by the majority of the scientific community [8], the actual most commonly employed methods of production are essentially simple post-processing developments of the conventional Bangham method $[9,10]$. This means that the most-used method for the production of these vesicles is thin-layer hydration [11,12], which was pioneered in 1970s, but after the very fast evolution of science, it became unacceptable to guarantee high-level quality and 
stability for human applications [13]. The main disadvantages were the low reproducibility of batch configurations, micrometric dimensions of vesicles produced, the necessity of post-processing steps, as well as the low encapsulation efficiency and the high solvent residue of ethanol or chloroform [14,15].

For all these reasons, $\mathrm{CO}_{2}$-assisted high-pressure methods have been proposed to solve almost all these problems [16,17], since carbon dioxide can be employed as a nontoxic co-solvent during drug carrier formation. Among the proposed techniques, SuperLip is a $\mathrm{CO}_{2}$-assisted process which inverts the traditional steps of hydration of a lipidic layer, by first creating the droplet of water and, then, a double lipidic layer around it [18]. This is guaranteed by a pressurized environment, where $\mathrm{CO}_{2}$ is mixed with ethanol, forming an expanded liquid, as a support for lipid deposition around water droplets. This process is already employed in some pharmaceutical, cosmetic, textile, and nutraceutical applications $[19,20]$, obtaining encapsulation efficiencies of hydrophilic, amphiphilic, and lipophilic compounds, up to $99 \%$ at nanometric level, with a low solvent residue and high cellular uptake. Additionally, the high time stability of liposomes produced in this manner has already been demonstrated using this process [21], as well as their capability to deliver entrapped molecules directly to the target cells [22].

This process has been employed several times for the encapsulation of hydrophilic and lipophilic active principles; in this paper, the encapsulation of a molecule with significant antioxidant properties [23,24], lutein, has been attempted. Lutein belongs to the family of carotenoids and has a high potential if used as a dietary supplement for the prevention of ocular illnesses involving retinal damages and cataracts [25], but it is also used to reduce cardiovascular disease risk [26], to replace yellow dyes in beverage coloration [27], and, last but not least, in anti-carcinogenic formulations. However, this molecule suffers for facile degradation, due to the exposition to light and heat; for this reason, the encapsulation in drug carriers such as liposomes enhances this molecule bioavailability, improving the effect on human cells [28-32].

Lutein has been successfully entrapped into liposomes using supercritical assisted techniques: in the work by Zhao et al., liposomes mean dimensions ranged between $148 \mathrm{~nm}$ and $195 \mathrm{~nm}$, while encapsulation efficiencies ranged between $57 \%$ and $97.8 \%$ [33]. In the work by Tan et al. [34], lutein loaded liposomes with diameters ranging between 76 and $135 \mathrm{~nm}$, and EE between $83 \%$ a $92 \%$.

In this study, the effect of SuperLip operating parameters has been investigated in order to provide controlled and tunable drug release, according to the time required by prolonged circulation of molecules until reaching target tissues. Despite the fact that SuperLip process has already been employed for the encapsulation of drugs for ocular delivery [35], the effect of process conditions on the post-production drug release administration has never been investigated. Another goal of this study is to propose the modelling of the raw data obtained from drug release, which has not been yet investigated on liposomes produced using SuperLip process. In this work, Weibull equation has been applied to raw data obtained from drug release tests.

\section{Materials and Methods}

\subsection{Materials}

L- $\alpha$-phosphatidylcholine from egg yolk (PC, about $60 \%$ purity) was purchased from Sigma-Aldrich, Milan, Italy and used as a source of phospholipids. Absolute ethanol (purity 99.8\%) was obtained from Carlo Erba, Milan, Italy. Carbon dioxide ( $>99.7 \%$ purity) was purchased from Morlando Group, Naples, Italy. Distilled water was produced directly in our laboratories. Lutein was provided by Shaanxi Superior Bio Technology Co., Shanxi, China; this company is a Natural Herbal Extract Manufacturer, that extracted lutein from marigold flowers. 


\subsection{Preparation of Preliminary Solutions}

In details, $500 \mathrm{mg}$ of phosphatidylcholine was dissolved in $100 \mathrm{~mL}$ ethanol by being stirred at room temperature at $300 \mathrm{rpm}$ for $20 \mathrm{~min}$. The solution was then filtered using grade 600 cellulose filter paper (Fisher Scientific, Milan, Italy), under vacuum. Then, $2.5 \mathrm{mg}$ or $5 \mathrm{mg}$ of lutein (depending on the chosen lipid to drug ratio) was dissolved in the filtered solution, in order to obtain $0.5 \% w / w$ or $1 \% w / w$ lutein to lipid feeding ratio. The final solution was left stirring at room temperature at $300 \mathrm{rpm}$ for $20 \mathrm{~min}$ more.

\subsection{Description of SuperLip Process Layout}

The description of the process is depicted in Figure 1 and is described as follows. This process is characterized by three feeding lines: carbon dioxide (P1), ethanol (P2), and water (P3), while the main elements are a High-Pressure Vessel (HPV) and a Separator (S), as reported in the sketch of Figure 1.

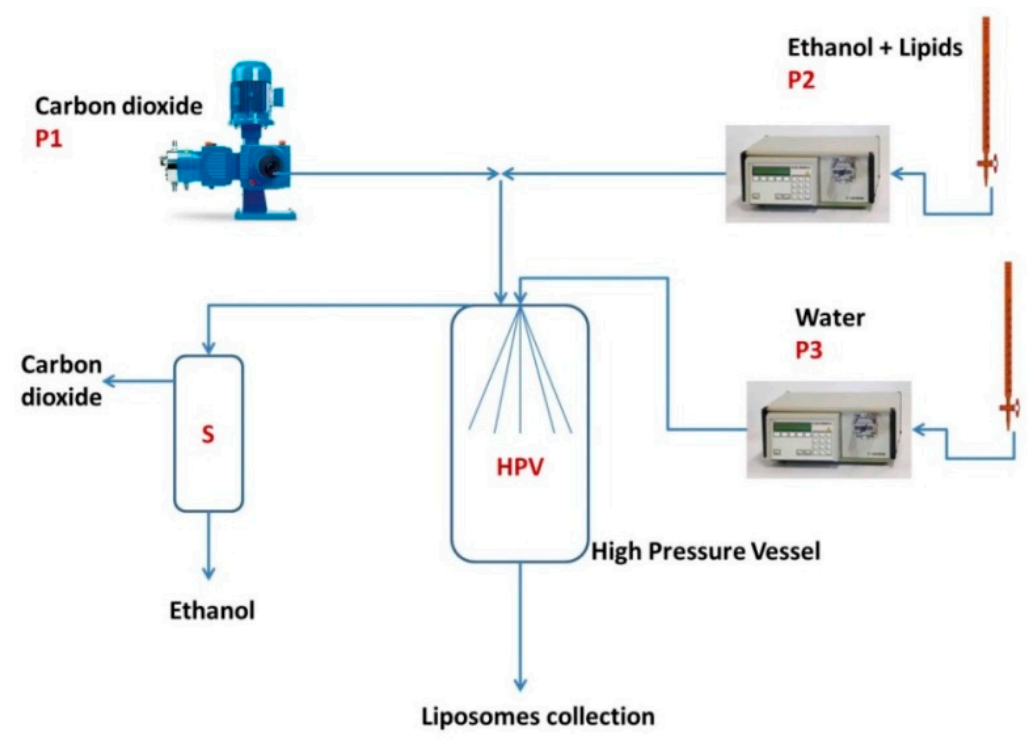

Figure 1. Experimental set-up of SuperLip process; $\mathrm{P} 1$ is the $\mathrm{CO}_{2}$ pump, $\mathrm{P} 2$ is the ethanol pump, $\mathrm{P} 3$ the water pump, S stands for Separator, HPV is the High-Pressure Vessel.

Liquid carbon dioxide was pumped to the system from a $30 \mathrm{~L}$ internal tank, where $\mathrm{CO}_{2}$ was stocked at a temperature of $25^{\circ} \mathrm{C}$ and 60 bar.

Carbon dioxide was pumped using an Ecoflow pump, mod. LDC-M-2, Lewa, Germany. The ethanol, in which lipids were previously dissolved, was pre-mixed with carbon dioxide, at a temperature of $40{ }^{\circ} \mathrm{C}$ and pressures of 100 or 150 bar. The mixer was a stainless-steel tank of $300 \mathrm{~cm}^{3}$, in which an expanded liquid was formed that was injected in the HPV (stainless-steel vessel of $500 \mathrm{~cm}^{3}$ with a height of $30 \mathrm{~cm}$ and internal diameter of $7.5 \mathrm{~cm}$ ). Water was directly pumped into the HPV, obtaining the droplets of water after high-pressure atomization using an $80 \mu \mathrm{m}$ nozzle. Water and carbon dioxide were continuously pumped to the system until the end of the ethanol solution. Water (P3) and ethanol (P2) were pumped using two different high pressure precision pumps (Model 305 , Gilson, France). Water flow rate was set at $10 \mathrm{~mL} / \mathrm{min}$, ethanol flow rate was set at $3.5 \mathrm{~mL} / \mathrm{min}$, corresponding to about $2.76 \mathrm{~g} / \mathrm{min}$ at the indicated conditions; whereas, carbon dioxide flow rate was set at $6.5 \mathrm{~g} / \mathrm{min}$. Flow rate ratio of carbon dioxide to ethanol was named Gas to Liquid Ratio (of the expanded liquid) and set at about 2.4 on mass basis.

Liposomes were continuously collected from the bottom of the high-pressure vessel using an on-off valve. A stainless-steel vessel (internal volume of $300 \mathrm{~cm}^{3}$ ) was used to separate ethanol and carbon dioxide from the liposomal solution, working at a slow decompression, down to 10 bar. At these conditions, carbon dioxide was separated from 
ethanol, and sent to a rotameter (mod. N.5-2500, Serval 115022, ASA, Italy) to measure $\mathrm{CO}_{2}$ flow rate, before being released to the atmosphere.

Experiments were performed with varying operating pressures (100 and 150 bars), temperatures $\left(35,40\right.$, and $\left.45^{\circ} \mathrm{C}\right)$, and drug to lipid ratios $(0.5$ and $1 \%, w / w)$. Each test belonging to this experimental campaign has been reported in Table 1 , together with its specific operating conditions of production.

Table 1. Experimental conditions (pressure, temperature, drug to lipid ratio) used in this process.

\begin{tabular}{cccc}
\hline Test Name & $\begin{array}{c}\text { Drug to Lipid Ratio } \\
(\mathbf{\%}, \boldsymbol{w} / \boldsymbol{w})\end{array}$ & Pressure (bar) & Temperature $\left({ }^{\circ} \mathbf{C}\right)$ \\
\hline Lut1 & 1 & 100 & 40 \\
Lut1 $^{\prime}$ & 1 & 100 & 40 \\
Lut1 & 1 & 100 & 40 \\
Lut2 & 1 & 100 & 35 \\
Lut3 & 1 & 100 & 45 \\
Lut4 & 1 & 150 & 35 \\
Lut5 & 1 & 150 & 45 \\
Lut6 & 0.5 & 100 & 35 \\
Lut7 & 0.5 & 100 & 45 \\
Lut8 & 0.5 & 150 & 35 \\
Lut9 & 0.5 & 150 & 45 \\
\hline
\end{tabular}

The liposomal suspensions obtained at these conditions were analyzed (liposome mean particle size, particle size distribution, and encapsulation efficiency) in order to determine the optimal operating conditions. Then, each sample was stocked in glass bottles and stored at $4{ }^{\circ} \mathrm{C}$ in the absence of light.

\subsection{Characterization of the Produced Samples}

Liposomal suspensions were characterized by a Dynamic Light Scattering (DLS) instrument (Zetasizer nano S, Alfatest, Cinisello Balsamo, Italy). These analyses allow the determination of the particle mean size and particle size distribution of liposomes in aqueous suspensions, considered as colloidal suspensions [36]. Liposome size was characterized in terms of Mean Diameter (MD), Standard Deviation (SD), and PolyDispersity Index (PDI). The light source of the Zetasizer instrument is a He-Ne laser $(4 \mathrm{~mW}, 633 \mathrm{~nm})$ and the backscatter angle is $173^{\circ}$. In this work, for each sample, 5 measurements were performed at $25^{\circ} \mathrm{C}$ in a $10 \mathrm{~mm}$ quartz glass cell (Hellma Italia Srl, Milan, Italy).

Then, 5 tubes (volume of $15 \mathrm{~mL}$ ) were used to prepare the sample for centrifugation. In each one, $13 \mathrm{~mL}$ of the liposomal suspension were added. The 5 tubes were balanced with a sixth one, of the same weight, loaded with the same weight of pure water. The samples were centrifuged for $60 \mathrm{~min}$, at $6500 \mathrm{rpm}$ and $-9^{\circ} \mathrm{C}$. After this operation, $4 \mathrm{~mL}$ of supernatant was removed from the top of the falcon and lutein absorbance was measured using a Micro-Volume UV-Vis Spectrophotometer (Biospec-nano, Shimadzu Scientific Instruments, Columbia, MD, USA). According to a calibration line previously obtained for lutein dissolved in a 50/50 $\mathrm{v} / \mathrm{v}$ ethanol/water solution, it was possible to determine the absorbance of lutein in the supernatant. Recalling the Lambert-Beer equation, absorbance was converted to concentration using the linear correlation. This gave the possibility to calculate the lutein entrapped percentage with respect to the initial lutein fed to the system, as the complement, to $100 \%$. The resulting number represented effective encapsulation efficiency (EE) in the double lipidic layer of liposomes, according to Equation (1).

The maximum lutein absorbance wavelength [37] was obtained by a spectrum measurement on lutein from $200 \mathrm{~nm}$ to $800 \mathrm{~nm}$; encapsulation efficiency tests and drug release 
tests were performed at the wavelength of $445 \mathrm{~nm}$, after detecting the maximum absorbance peak on a lutein spectrum.

$$
\mathrm{EE}(\%)=\frac{[\text { Lutein Total }]-[\text { Lutein Free }]}{[\text { Lutein Total }]} \times 100
$$

Encapsulation efficiencies are reported in terms of mean values and standard deviations, after three runs and 5 measurements repetitions.

\subsection{Scanning Electron Microscope Observations}

The morphology of the vesicles produced using SuperLip process was observed using a Scanning Electron Microscope (SEM mod. LEO 1525; Carl Zeiss SMT AG, Oberkochen, Germany). A drop of liposome suspension was spread on a carbon tab placed on an aluminum stub and dried at air for $48 \mathrm{~h}$. Then, dried samples were coated with a gold layer using a sputter coater (thickness $250 \AA$, model B7341; Agar Scientific, Stansted, UK). After becoming conducible, samples were observed using SEM.

\subsection{Drug Release Test}

Drug release tests were also performed for SuperLip-produced vesicles. The external bulk used for drug release in this work was Phosphate Buffer Saline (PBS). It was prepared in this manner: $8 \mathrm{~g} \mathrm{NaCl}, 0.2 \mathrm{~g} \mathrm{KCl}, 1.44 \mathrm{~g} \mathrm{Na}_{2} \mathrm{HPO}_{4}, 0.24 \mathrm{~g} \mathrm{KH}_{2} \mathrm{PO}_{4}$ for $1 \mathrm{~L}$ distilled water. The 7-cm-long membranes (or dialysis sacks, $12 \mathrm{kDa}$ cut-off) were washed in a bath prepared dissolving $146 \mathrm{~g}$ Ethylene Diamine Tetraacetic acid (EDTA, $\mathrm{C}_{10} \mathrm{H}_{16} \mathrm{~N}_{2} \mathrm{O}_{8}$ ) and $10 \mathrm{mg}$ Sodium Bicarbonate $\left(\mathrm{NaHCO}_{3}\right)$ in $500 \mathrm{~mL}$ distilled water. In each experiment, the dialysis sack was submerged in the washing bath at $50{ }^{\circ} \mathrm{C}$ for $30 \mathrm{~min}$. Then, the membrane was clamped from one side, and $5 \mathrm{~mL}$ liposomal suspension was added inside, together with a magnet for internal stirring, and then it was clamped also from the other side. Then, the double-clamped membrane was added to a $300 \mathrm{~mL}$ PBS volume of external bulk, pre-heated at a temperature of $37^{\circ} \mathrm{C}$ (considered the average human body temperature). The external bulk was also stirred with another larger magnet. The same probe of the Micro-Volume UV-Vis Spectrophotometer (Biospec-nano, Shimadzu Scientific Instruments, Columbia, MD, USA) was used to measure the absorbance of lutein released in the external bulk. Additionally, in this case, the absorbance of lutein was continuously measured at the same wavelength of $445 \mathrm{~nm}$, using another lutein calibration line, obtained in PBS buffer. Drug release tests were observed until $110 \mathrm{~h}$, corresponding to about 4.5 days.

\subsection{Drug Release Raw Data Modelling}

Mathematical modelling has been applied to model drug release raw data from liposomes [36,37]. In this work, raw data obtained from drug release tests were modelled according to Weibull equation [38-40], according to Equation (2).

$$
y=A\left(1-e^{-\left(k\left(t-t_{c}\right)\right)^{d}}\right)
$$

In this equation, $A$ is the amplitude (100\%) of the release percentage, whereas $t$ is the time and $t_{c}$ is the central value of time, while $k$ and $d$ are the two working variables.

Diagrams reported in the final section of results show the raw data and their fitting curve; model parameters and $\mathrm{R}^{2}$ values are tabled at the end.

\section{Results}

\subsection{Repeatability Experiments}

The typical SuperLip experiment consisted in preparing the three feeding lines: ethanol containing $500 \mathrm{mg}$ phospholipids and the defined amount of lutein, carbon dioxide, and pure water. These three species were pumped to the system until reaching steady state conditions. To demonstrate the advantages of the continuity of this process, experiments of repeatability were performed, in different days, using newly prepared ethanolic solutions, 
working at 100 bar and setting the temperature at $40{ }^{\circ} \mathrm{C}$ and the drug to lipid ratio at $1 \%$ on mass basis. The operator was always the same and the DLS and Encapsulation efficiency (EE) measurements were performed for each run. Results are reported in Table 2.

Table 2. Mean diameter (MD), PolyDispersity Index (PDI), and encapsulation efficiency (EE) obtained in reproducibility tests.

\begin{tabular}{cccc}
\hline Test & MD \pm SD (nm) & PDI & EE \pm SD (\%) \\
\hline Lut1 & $153 \pm 38$ & 0.25 & $86.5 \pm 0.4$ \\
Lut1 & $176 \pm 40$ & 0.23 & $87.1 \pm 1.0$ \\
Lut1 $^{\prime \prime}$ & $169 \pm 44$ & 0.26 & $89.5 \pm 0.6$ \\
\hline
\end{tabular}

As it is possible to see in Table 2 and Figure 2, the three experiments gave almost repeatable data (Lut1, Lut1', and Lut1"). In particular, Lut1 had mean diameter of $153 \pm 38 \mathrm{~nm}$, Lut1' was $176 \pm 40 \mathrm{~nm}$ large, and Lut1" had mean dimensions of $169 \pm 44 \mathrm{~nm}$. The three particle size distributions have a similar PDI. According to the direct use of liposomes, this process is able to produce one-shot nanometric liposomes that are directly available for drug release; mean dimensions lower than $200 \mathrm{~nm}$ are also available for biomedical and pharmaceutical applications [41,42]. These repeatability data were also confirmed by SEM images reported in the following part of this results section. Moreover, the encapsulation efficiencies of lutein were similar, with values between $86.5 \pm 0.4 \%$ and $89.5 \pm 0.6 \%$.

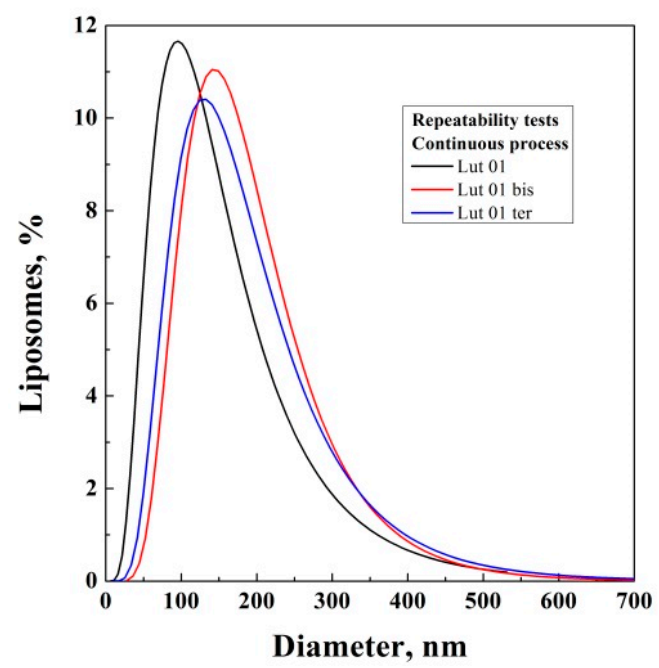

Figure 2. Particle size distribution obtained in repeatability tests.

\subsection{Study of the Effect of Operating Parameters}

The effect of operating temperature on mean particle size and lutein encapsulation efficiency on the liposomes produced using SuperLip, was studied at $35{ }^{\circ} \mathrm{C}, 40{ }^{\circ} \mathrm{C}$, and $45^{\circ} \mathrm{C}$. These temperatures were chosen in order to inhibit chemical degradation of carotenoids $[43,44]$, maintaining their physical properties. Therefore, lutein is subject to minimum degradation at temperatures lower than $60^{\circ} \mathrm{C}$ [45]. Moreover, the critical temperature of carbon dioxide is reached at $31.1^{\circ} \mathrm{C}$. Setting the lower limit of $31.1^{\circ} \mathrm{C}$ and the higher limit of $60^{\circ} \mathrm{C}$, we decided to work in a thin temperature operating window among $35^{\circ} \mathrm{C}$ and $45^{\circ} \mathrm{C}$.

The variation of temperature did not have a significant effect on the particle size distribution, but it influenced the permeability of the double lipidic layer of the liposomes produced. In the literature, one of the most studied effects regards the drug release activated by an external stimulus such as the increase of temperature $[46,47]$; the increase of temperature could facilitate drug release, since the external lipidic barrier improves its permeability after receiving the stimulus. Therefore, in this study, we applied this theory 
of the fast diffusion to the liposomes produced at a higher temperature, which could be employed for a fast drug administration, while protecting lutein from degradation. Since in this work, we employed carbon dioxide as co-solvent medium, the low critical temperature of $\mathrm{CO}_{2}\left(31.1^{\circ} \mathrm{C}\right)$ allowed us to process lutein without any risk of thermal degradation.

Then, the effect of pressure was studied (100 and 150 bar), by leaving constant the temperature at $35{ }^{\circ} \mathrm{C}$ and drug to lipid ratio at $1 \%$ on mass basis. At the end, the effect of DLR was studied ( $0.5 \%$ and $1 \%$ on mass basis) by leaving the pressure constant at 100 bar and the temperature at $45^{\circ} \mathrm{C}$. Results are reported in Table 3.

Table 3. Size, size distribution, and encapsulation efficiency for the experimental design performed for the encapsulation of lutein.

\begin{tabular}{cccccc}
\hline Test & $\begin{array}{c}\text { Pressure } \\
\text { (bar) }\end{array}$ & $\begin{array}{c}\text { Temperature } \\
\left({ }^{\circ} \mathbf{C}\right)\end{array}$ & $\begin{array}{c}\text { Drug to } \\
\text { Lipid Ratio } \\
\text { (\% mass) }\end{array}$ & $\begin{array}{c}\text { Liposome Mean } \\
\text { Diameter } \\
\text { nm (MD } \pm \text { SD) }\end{array}$ & $\begin{array}{c}\text { Encapsulation } \\
\text { Efficiency } \\
\text { \% (EE } \pm \text { SD) }\end{array}$ \\
\hline Lut1 & 100 & 40 & 1 & $153 \pm 38$ & $86.5 \pm 0.4$ \\
Lut2 & 100 & 35 & 1 & $206 \pm 41$ & $97.1 \pm 0.5$ \\
Lut3 & 100 & 45 & 1 & $267 \pm 56$ & $96.0 \pm 0.2$ \\
Lut4 & 150 & 35 & 1 & $192 \pm 38$ & $88.0 \pm 1.2$ \\
Lut5 & 150 & 45 & 1 & $196 \pm 39$ & $87.0 \pm 0.1$ \\
Lut6 & 100 & 35 & 0.5 & $145 \pm 54$ & $97.8 \pm 1.2$ \\
Lut7 & 100 & 45 & 0.5 & $163 \pm 39$ & $86.7 \pm 1.6$ \\
Lut8 & 150 & 35 & 0.5 & $158 \pm 55$ & $91.3 \pm 2.2$ \\
Lut9 & 150 & 45 & 0.5 & $178 \pm 63$ & $84.7 \pm 2.5$ \\
\hline
\end{tabular}

According to the operating conditions in the first set of experiments, the sample named Lut1 produced liposomes of $153 \pm 38 \mathrm{~nm}$, working at $40{ }^{\circ} \mathrm{C}, 100 \mathrm{bar}$, and $1 \%$ DLR. Then, the sample named Lut2 was produced at $35^{\circ} \mathrm{C}$, with the same pressure and DLR, obtaining a mean value of $206 \pm 41 \mathrm{~nm}$. The reduction of temperatures produced an increase of mean diameter of about $50 \mathrm{~nm}$. However, when the temperature was further increased to $45^{\circ} \mathrm{C}$, (experiment named Lut3), the mean size became $267 \pm 56 \mathrm{~nm}$ (see Figure 3a). Even if the temperature was increased from $35^{\circ} \mathrm{C}$ to $45^{\circ} \mathrm{C}$, there was not a dramatic increase of the mean size of liposomes, according to the mean dimensions needed for pharmaceutical issues [48,49]; moreover, the encapsulation of lutein was still successful and could be applied for specific cellular applications.

The effect of pressure was also studied (see Figure $3 b$ ). Liposomes produced at $35{ }^{\circ} \mathrm{C}$ (Lut2) gave a mean diameter of $206 \pm 41 \mathrm{~nm}$ at 100 bar; however, by increasing the pressure at 150 bar and leaving the temperature at $35{ }^{\circ} \mathrm{C}$ (Lut4) and DLR at $1 \% w / w$, the mean size of liposomes became $192 \pm 38 \mathrm{~nm}$, with a similar mean size and standard deviation (Figure $3 b$ ). Even if the mean size =variation did not follow the increase of temperature, the EE was $97.1 \pm 0.5 \%$ for Lut 2 and $88.0 \pm 1.2 \%$ for Lut 4 . This was not necessarily linked to pressure variation. The Lut 5 experiments was produced at $45^{\circ} \mathrm{C}$ and 150 bar (leaving DLR constant at $1 \% w / w$ ), showing a mean size of $178 \pm 63 \mathrm{~nm}$ and an EE of $87.0 \pm 0.1 \%$, obtaining EE overlapping results with Lut4.

At the end of this campaign of experiments, the effect of the drug to lipid ratio was studied. The drug to lipid ratio was reduced to $0.5 \% w / w$. At 100 bar and $35{ }^{\circ} \mathrm{C}$ (Lut6), $145 \pm 54 \mathrm{~nm}$ liposomes were produced, with an EE of $97.8 \pm 1.2 \%$, which was the highest value obtained in terms of drug EE for this designed process for lutein encapsulation. Indeed, the reduced amount of lutein entrapped in the double layer of phospholipids contributed to reduce particle mean size, resulting in a reduced space occupied by drugs in the external region of vesicles. However, when the temperature was increased to $45{ }^{\circ} \mathrm{C}$ (Lut7), liposomes produced showed a mean size of $163 \pm 39 \mathrm{~nm}$ and an EE of $86.7 \pm 1.6 \%$. The last case regards the reduced DLR to $0.5 \% w / w$ and the increased pressure to 150 bar: in the case of $35{ }^{\circ} \mathrm{C}$ (Lut8), mean size is $158 \pm 55 \mathrm{~nm}$ and EE of $91.3 \pm 2.2 \%$, whereas at $45^{\circ} \mathrm{C}$ (Lut9), mean dimensions are $178 \pm 63 \mathrm{~nm}$ and EE $84.7 \pm 2.5 \%$. Again, a decreased temperature contributed to higher encapsulation efficiency, due to the fact that the external 
lipidic barrier becomes more compact than the one obtained during a higher temperature SuperLip process $\left(45^{\circ} \mathrm{C}\right)$.

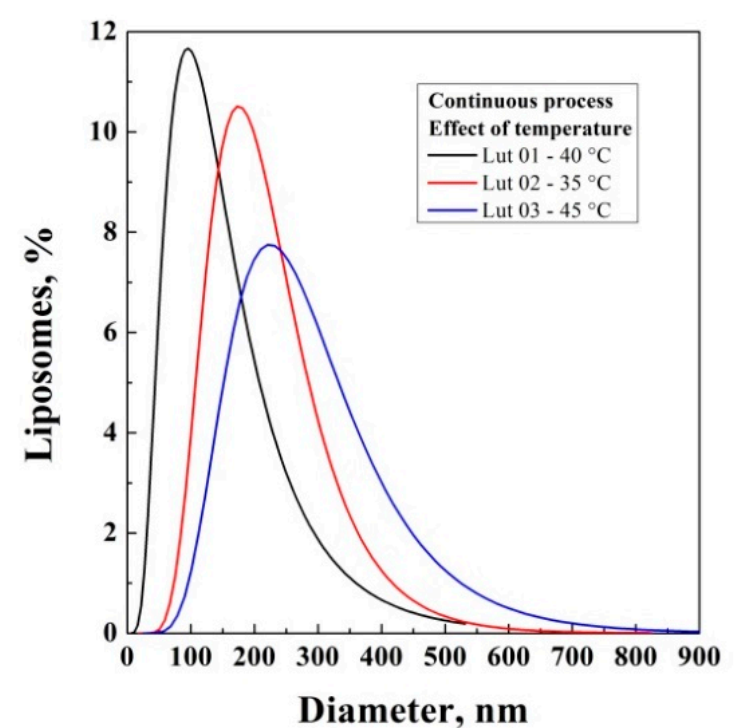

(a)

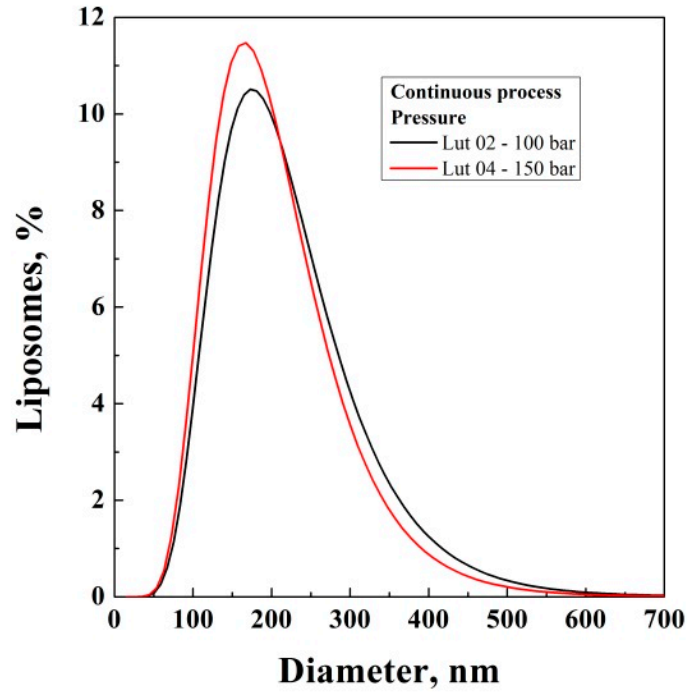

(b)

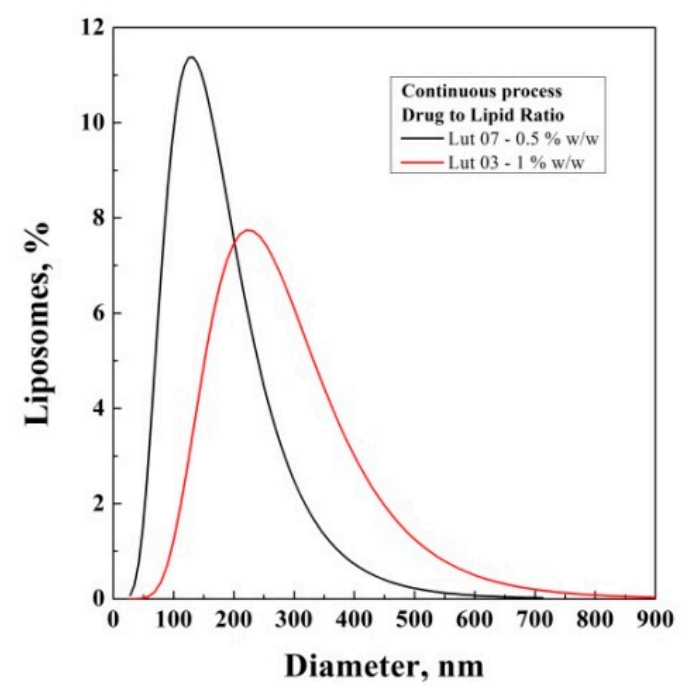

(c)

Figure 3. Influence of temperature on liposome mean dimensions for a pressure of 100 bar and a drug to lipid ratio of $1 \%$ mass (a); influence of operating pressure on liposome size distribution for a drug to lipid ratio of $1 \% w / w$ and a temperature of $35^{\circ} \mathrm{C}(\mathbf{b})$; influence of lutein to lipid ratio on liposome size distribution for a pressure of 100 bar and a temperature of $45^{\circ} \mathrm{C}(\mathbf{c})$.

\subsection{Scanning Electron Microscope Observations}

Liposomes produced using SuperLip were observed using a Scanning Electron Microscope, following the protocol described in Methods section.

Liposomes shown in Figure 4 are representatives of samples produced at 100 and 150 bar, among $35{ }^{\circ} \mathrm{C}$ and $45{ }^{\circ} \mathrm{C}$, and DLR among $0.5 \%$ and $1 \%$, thus resulting in the production of vesicles whose mean diameter is included among 200 and $300 \mathrm{~nm}$, as confirmed by DLS analysis reported in Table 3. In all cases, liposomes have a spherical shape and smooth surface. As it is possible to see in all these SEM figures, the aggregation of lipids is due to the drying that was performed during liposomes preparation for SEM characterization, as reported in the preparation protocol of the Methods section. 


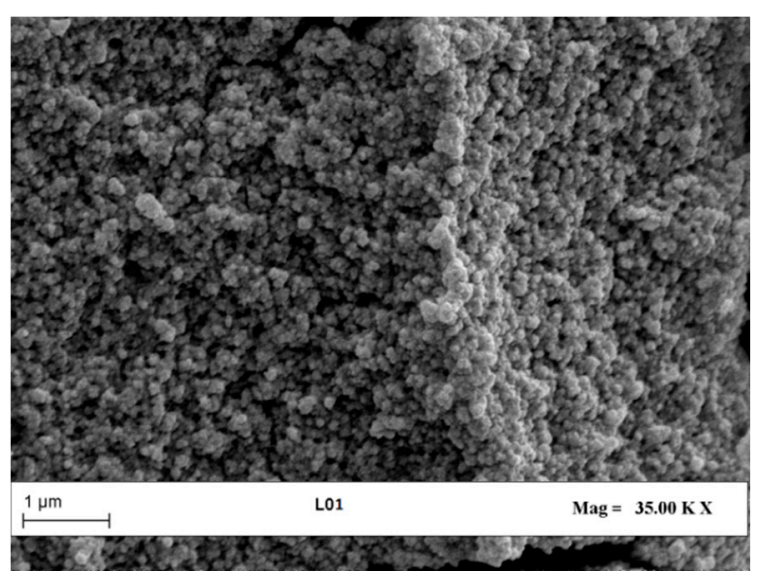

(a)

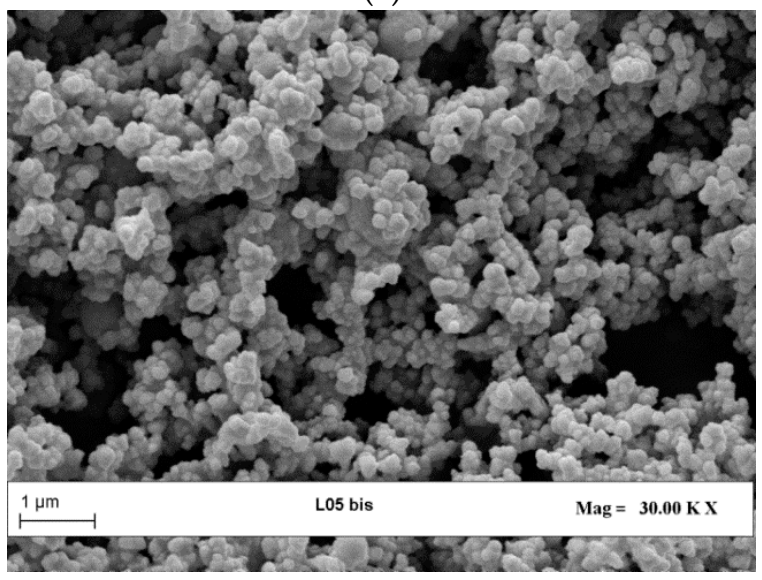

(c)

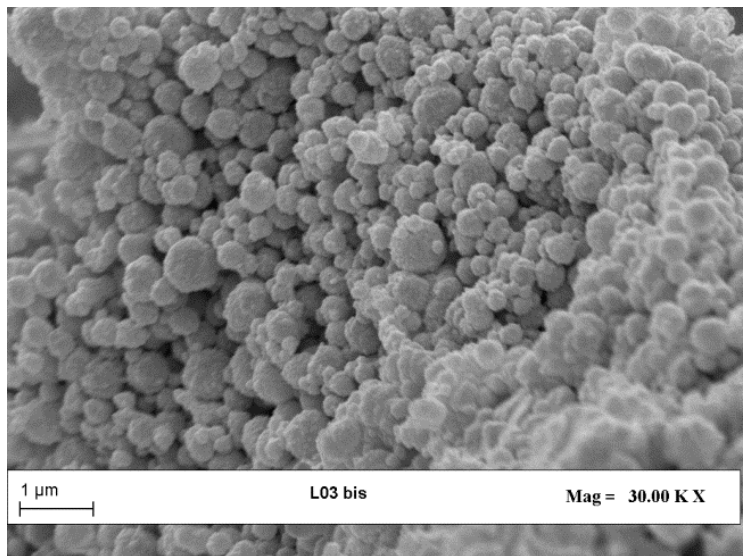

(b)

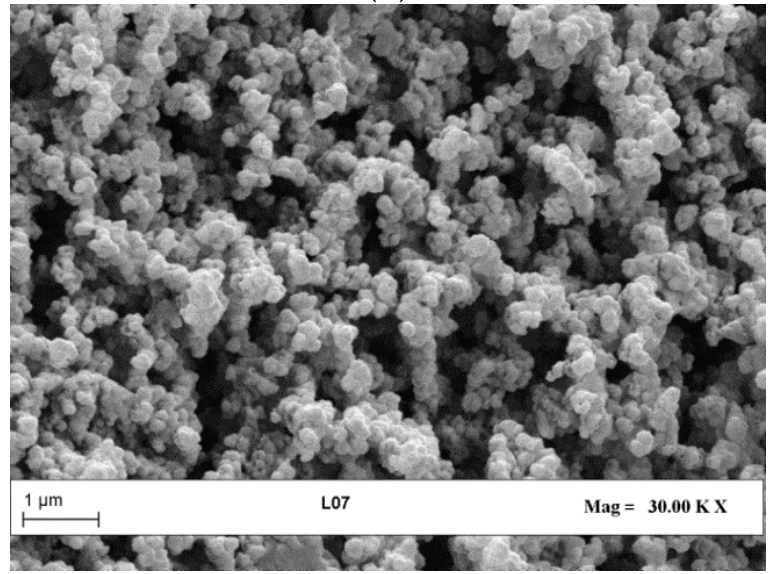

(d)

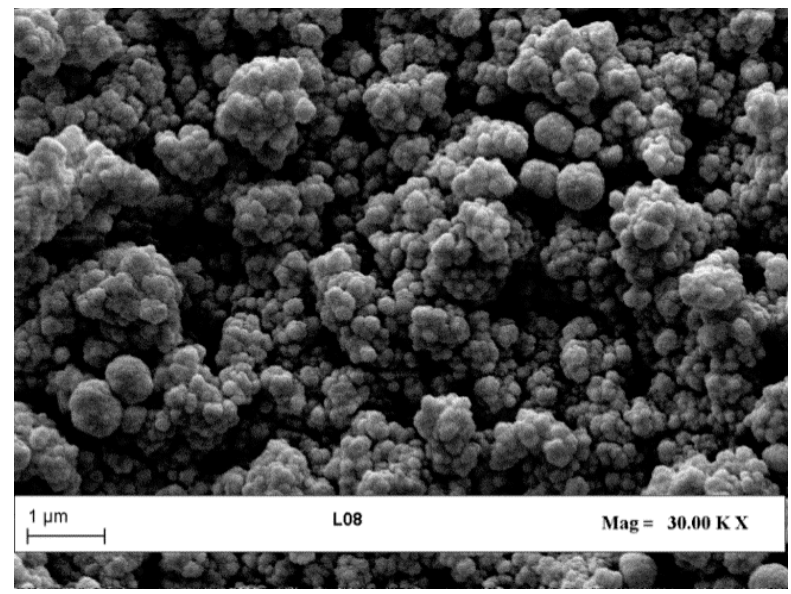

(e)

Figure 4. Scanning Electron Microscope observations of liposomes produced using SuperLip. (a) Lut1 (100 bar, $35^{\circ} \mathrm{C}$, and $1 \%$ DLR), (b) Lut3 (100 bar, $45^{\circ} \mathrm{C}$, and 1\% DLR), (c) Lut 5 (150 bar, $45^{\circ} \mathrm{C}$, and $1 \%$ DLR), (d) Lut7 $\left(100\right.$ bar, $\left.45^{\circ} \mathrm{C}, 0.5 \%\right)$, (e) Lut8 (150 bar, $35^{\circ} \mathrm{C}, 0.5 \%$ DLR).

\subsection{Drug Release Tests and Modelling}

At the end of this study, Drug Release (DR) tests were performed from liposomes produced during experiments Lut 1, Lut 2, and Lut 3. These samples are referred to vesicles produced with SuperLip at 100 bar, 1\% w/w DLR, and a working temperature of $35^{\circ} \mathrm{C}$, $40{ }^{\circ} \mathrm{C}$, and $45^{\circ} \mathrm{C}$, respectively. The choice is due to the fact that in this set, the average EE was the highest $(86 \%, 97 \%$, and $96 \%)$. Even if drug release tests were performed at a 
constant temperature of $37^{\circ} \mathrm{C}$, the effect of the temperature used for producing samples was studied during drug release tests and shown in Figure 5.

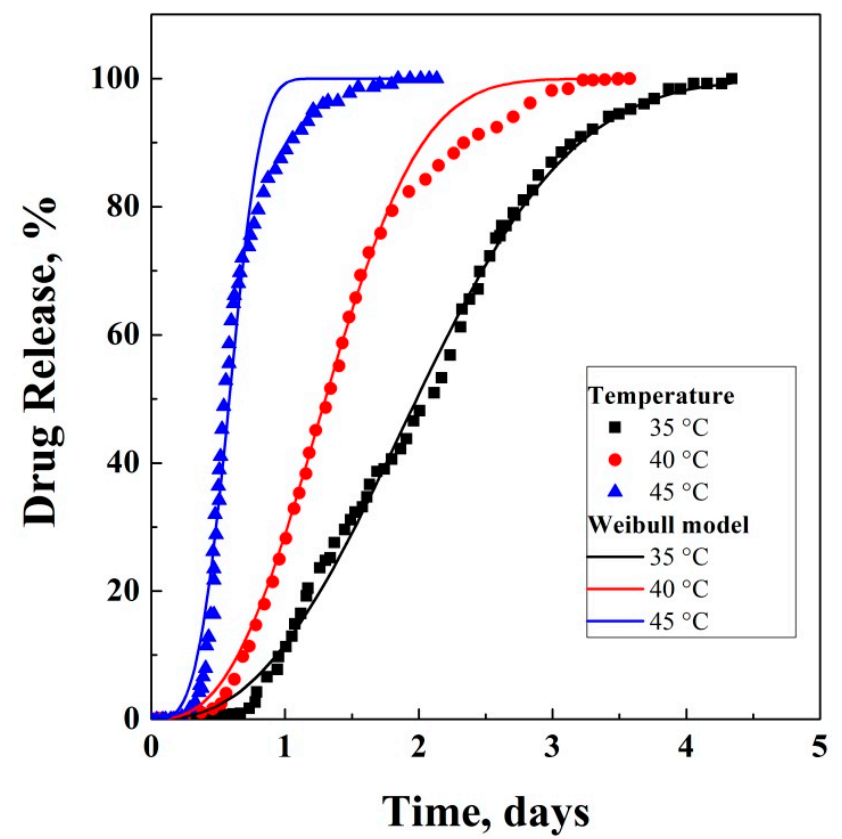

Figure 5. Drug release test comparison from liposomes, as an effect of liposomes produced at different temperatures.

The drug release of the experiment produced at $35{ }^{\circ} \mathrm{C}$ ended in about 4.5 days, with a significant delay time of 0.8 days before liposomes started to release lutein. A similar behavior was registered for drug release from liposomes produced at $40{ }^{\circ} \mathrm{C}$, where the initial delay was about 0.6 days and it released all the drug content in 3 days. The third test, related to vesicles produced at $45^{\circ} \mathrm{C}$, was faster than previously analyzed ones, ending in less than 2 days.

Therefore, an evident and expected effect was detected: by increasing the production temperature, drug release was enhanced. A possible explanation of this trend is that the increase in the temperature from $35^{\circ} \mathrm{C}$ to $45^{\circ} \mathrm{C}$ reduced the strength of the lipidic barrier of liposomes, favoring a faster drug release. This indication is also confirmed by the fact that liposomes can release their content after production at an increased temperature. Moreover, the higher production temperature resulted in the production of liposomes with a less compact structure; this fact favored drug release performed in the receiving liquid medium.

As indicated above, drug release raw data were modelled according to Weibull model [50-52], to which literature refers as being generally used for drug release. In Figure 5, raw data obtained from drug release of liposomes prepared at 35,40 , and $45^{\circ} \mathrm{C}$, respectively, were fitted. The main parameters and the $\mathrm{R}^{2}$ obtained for the model are reported in Table 4.

Table 4. Weibull model parameters at each process temperature (as reported in Equation (2)).

\begin{tabular}{cccccc}
\hline Temperature & $\mathbf{A}$ & $\mathbf{d}$ & $\mathbf{K}$ & $\mathbf{R}^{\mathbf{2}}$ & Temperature \\
\hline $35^{\circ} \mathrm{C}$ & 100 & 2.504 & 0.435 & 0.997 & $35^{\circ} \mathrm{C}$ \\
$40^{\circ} \mathrm{C}$ & 100 & 2.693 & 0.670 & 0.995 & $40^{\circ} \mathrm{C}$ \\
$45^{\circ} \mathrm{C}$ & 100 & 3.596 & 1.549 & 0.975 & $45^{\circ} \mathrm{C}$ \\
\hline
\end{tabular}

As it is possible to see from Figure 5 and Table 4, raw data of drug release from liposomes prepared at $35{ }^{\circ} \mathrm{C}$ showed $\mathrm{R}^{2}$ value of $99.7 \%$. The only set parameter was the amplitude, which was blocked at $100 \%$, indicating the asymptotic total drug loss from 
liposomes. Drug release performed from liposomes prepared at $40{ }^{\circ} \mathrm{C}$ did not result in a $\mathrm{R}^{2}$ value of $99.7 \%$, even if the fitting parameters were significantly different. In the case of drug release from liposomes produced at $45^{\circ} \mathrm{C}$, the $\mathrm{R}^{2}$ value was reduced to $97.5 \%$. In this last case, the main controlling phenomenon was the drug diffusion from the inner core to the external bulk, but the less compact structure of liposomes contributed to allow a faster release of lutein. For this reason, the shape of the curve changed at $45^{\circ} \mathrm{C}$, and in this case, the model did not fit the raw data as well as in the case of lower temperatures.

\section{Discussion}

Drug carriers have been developed to overcome several problems of drug degradation and boor bioavailability that occurred frequently during administration to human tissues. The idea of protecting these drugs and active principles was successful, since an external shell or double layer (made of phospholipids or polymers) was able to avoid destructive interferences by external stimuli such as light or heat. This was particularly effective for antioxidant compounds, which are particularly sensitive to the conditions of human blood (temperature, $\mathrm{pH}$, immune response). In particular, drugs were often recognized by the immune systems as intrusive and toxic, and was systematically attacked and eliminated by phagocytes and macrophages. Moreover, the simple drug delivery through the gastrointestinal tract was particularly ineffective, due to the high acidic conditions $(\mathrm{pH}<2)$. All these drawbacks were solved by the use of drug carriers; in particular, liposomes were the most effective carriers, since they were characterized and constituted by the same backbone of human cells.

From one side, an intelligent solution was achieved; however, another problem became particularly critical for liposomes, and it was related to the method of production. Liposomes are spherical vesicles, but the mean dimensions, the stability over time, and the encapsulation efficiencies were critical parameters to control and monitor during and after the production. As was highlighted in the literature, the conventional methods for the production of liposomes suffered of low reproducibility and low encapsulation efficiencies of molecules. Several papers reported in the literature were finalized at the creation of liposomes in a batch mode, but they often needed post-processing steps of refining, such as filtration, sonication, or extrusion, in order to obtain nanometric mean dimensions. This created mechanical stress to the production of liposomes, often resulting in a loss of a significant fraction of the drug entrapped in the inner core or in the double lipidic layer. Moreover, some kinds of phospholipids are well-known temperature-sensitive materials, especially in relation to their phase transition behavior from gel phase to crystalline phase. The temperature of transition also depends on the type of phospholipid employed; this could impact to drug release behavior [53,54].

The specific problem of production was resolved by the idea to work at high pressures, using carbon dioxide in supercritical conditions. $\mathrm{CO}_{2}$ is a cheap, non-toxic solvent, that has the ability to work in the place of the traditional solvent extraction. $\mathrm{CO}_{2}$, working in a mixture with an organic solvent, can create an expanded liquid; this mixture has the ability to extract a specific solute, or induce an assisted atomization or even precipitation. Exploited by different high-pressure technologies, these phenomena have the ability to create drug carriers, with the great advantage to eliminate the organic solvent from the final product. The organic solvent is eliminated by carbon dioxide, while high-pressure conditions induce a fast and one-shot production of particles at nanometric dimensions. The process proposed in this paper and named SuperLip, after being employed several times in the literature, has also been capable of significantly reducing the ethanol residue in the final liposomes formulations. Moreover, liposomes produced using SuperLip were of nanometric dimensions, with high encapsulation efficiencies of hydrophilic and lipophilic compounds; that is why it was employed in this work for the secure and successful entrapment of lutein.

However, as it is possible to see from the results, the idea of this work was not only the encapsulation of lutein into liposomes, but also to try to tune drug release of lutein by 
varying the production operating parameters $[55,56]$. Among all the parameters studied in this paper, it was particularly interesting the effect of operating temperature on the successive drug release performed after the production. There is a substantial difference among the production of temperature-sensitive liposomes and the liposomes whose drug release is tuned by operating temperature. In the first case, liposomes are made of specific and expensive phospholipids, and are prepared in such a manner that they can open their structure and release their content only when a sudden external increase of temperature is applied. Instead, in this work, a different phenomenon was studied: the possibility to create a double lipidic layer with different resistance to mass transfer of lutein among the internal regions and the external bulk. In this case, the drug release was faster or slower, depending on the temperature of the process during production, and without the addition of external stimuli during the subsequent drug release.

The effect of the producing temperature on the external barrier structure of liposomes was studied in this work. The possibility to regulate the properties of liposomes' surfaces and the double lipidic layer was a particularly ambitious goal, which was achieved by creating temperature-responsive surfaces of liposomes. This fact was demonstrated by the effect on drug release profiles obtained, as it is possible to see in the Results section. In detail, the release was faster by increasing the production temperature, which resulted into a reduced robustness of the external double lipidic layer.

\section{Conclusions}

This work was aimed at producing liposomes whose drug release could be tunable, by varying the temperature of production. The innovation proposed was not focused on the supercritical technique for the production of liposomes, which has been demonstrated many times under different pharmaceutical applications, but it aimed at producing liposomes whose drug release could be regulated, in order to find specific therapeutic necessities of the human body.

Liposomes obtained in this work were produced one-shot at nanometric level, with mean diameters between 137 and $267 \mathrm{~nm}$, and lutein encapsulation efficiency up to $98 \%$, using a protocol validated by the literature and based on the elimination of the supernatant. The effect of drug to lipid ratio, pressure, and temperature was studied on mean size and EE, and mean dimensions were not significantly affected by the variation of these parameters.

The use of Weibull equation for the modelling of drug release raw data was investigated for the first time for liposomes produced using SuperLip. Liposomes produced with a higher temperature can be used in cases in which the drug release needs to be addressed in less time. This concept was also confirmed by the modelling part of this work, which completely fitted the raw data of release profiles at $35^{\circ} \mathrm{C}$ and $40^{\circ} \mathrm{C}$, while losing fitting precision on raw data obtained at $45^{\circ} \mathrm{C}$.

Therefore, for vesicles produced at higher temperatures, a further comment could be that a model should also contain a dependency on temperature parameter. The study and production of these kinds of temperature-responsive liposomes using high-pressure continuous methods, could open new roots to the definitions of temperature-responsive vesicles; this could be a preliminary work that had the ambition to optimize and regulate processing parameters, but it will require further in vivo studies performed in sterile conditions by researchers from departments of medicine.

Author Contributions: Conceptualization, P.T. and M.M.; methodology, P.T. and M.M.; software, P.T.; investigation, P.T.; data curation, P.T.; writing-original draft preparation, P.T. and E.R.; writingreview and editing, P.T. and E.R.; supervision, E.R. All authors have read and agreed to the published version of the manuscript.

Funding: This research received no external funding.

Institutional Review Board Statement: Not applicable.

Informed Consent Statement: Not applicable. 


\section{Data Availability Statement: Not applicable.}

Conflicts of Interest: The authors declare no conflict of interest.

$\begin{array}{ll}\text { Abbreviations } \\ \text { DDS } & \text { Drug Delivery Systems } \\ \text { EE } & \text { Encapsulation Efficiency } \\ \text { PSD } & \text { Particle Size Distribution } \\ \text { PDI } & \text { Polydispersity Index } \\ \text { SD } & \text { Standard Deviation } \\ \text { MD } & \text { Mean Diameter } \\ \text { DLS } & \text { Dynamic Light Scattering } \\ \text { SEM } & \text { Scanning Electron Microscope } \\ \text { DR } & \text { Drug Release } \\ \text { HPV } & \text { High-Pressure Vessel } \\ \text { S } & \text { Separator } \\ \text { PC } & \text { L- } \alpha \text {-phosphatidylcholine }\end{array}$

\section{References}

1. Allen, T.M. Drug Delivery Systems: Entering the Mainstream. Science 2004, 303, 1818-1822. [CrossRef] [PubMed]

2. Lavik, E.B.; Kuehn, M.H.; Kwon, Y. Novel drug delivery systems for glaucoma. Eye 2011, 25, 578-586. [CrossRef] [PubMed]

3. Crommelin, D.J.A.; Storm, G. Liposomes: From the Bench to the Bed. J. Liposome Res. 2003, 13, 33-36. [CrossRef] [PubMed]

4. Tsai, W.-C.; Rizvi, S. Simultaneous microencapsulation of hydrophilic and lipophilic bioactives in liposomes produced by an ecofriendly supercritical fluid process. Food Res. Int. 2017, 99, 256-262. [CrossRef]

5. Fatouros, D.G.; Antimisiaris, S.G. Effect of Amphiphilic Drugs on the Stability and Zeta-Potential of Their Liposome Formulations: A Study with Prednisolone, Diazepam, and Griseofulvin. J. Colloid Interface Sci. 2002, 251, 271-277. [CrossRef]

6. Mallick, S.; Choi, J.S. Liposomes: Versatile and Biocompatible Nanovesicles for Efficient Biomolecules Delivery. J. Nanosci. Nanotechnol. 2014, 14, 755-765. [CrossRef]

7. Alavi, M.; Asare-Addo, K.; Nokhodchi, A. Lectin Protein as a Promising Component to Functionalize Micelles, Liposomes and Lipid NPs against Coronavirus. Biomedicine 2020, 8, 580. [CrossRef]

8. Mozafari, M.R. Liposomes: An overview of manufacturing techniques. Cell. Mol. Biol. Lett. 2005, 10, 711-719. Available online: https:/ / europepmc.org/article/med/16341279 (accessed on 5 June 2021).

9. Meure, L.A.; Foster, N.R.; Dehghani, F. Conventional and Dense Gas Techniques for the Production of Liposomes: A Review. AAPS PharmSciTech 2008, 9, 798-809. [CrossRef]

10. William, B.; Noémie, P.; Brigitte, E.; Géraldine, P. Supercritical fluid methods: An alternative to conventional methods to prepare liposomes. Chem. Eng. J. 2020, 383, 123106. [CrossRef]

11. Trucillo, P.; Campardelli, R.; Reverchon, E. Liposomes: From Bangham to Supercritical Fluids. Processes 2020, 8, 1022. [CrossRef]

12. Patil, Y.P.; Jadhav, S. Novel methods for liposome preparation. Chem. Phys. Lipids 2014, 177, 8-18. [CrossRef] [PubMed]

13. Deamer, D.W. From "Banghasomes" to liposomes: A memoir of Alec Bangham, 1921-2010. FASEB J. 2010, 24, 1308-1310. [CrossRef]

14. Maherani, B.; Arab-Tehrany, E.; Mozafari, M.R.; Gaiani, C.; Linder, M. Liposomes: A Review of Manufacturing Techniques and Targeting Strategies. Curr. Nanosci. 2011, 7, 436-452. [CrossRef]

15. Sultana, Y.; Aqil, M. Liposomal Drug Delivery Systems: An Update Review. Curr. Drug Deliv. 2007, 4, 297-305. [CrossRef]

16. Liu, G.; Hou, S.; Tong, P.; Li, J. Liposomes: Preparation, Characteristics, and Application Strategies in Analytical Chemistry. Crit. Rev. Anal. Chem. 2020, 1-21. [CrossRef]

17. Has, C.; Sunthar, P. A comprehensive review on recent preparation techniques of liposomes. J. Liposome Res. 2020, 30, 336-365. [CrossRef]

18. Trucillo, P.; Reverchon, E. Production of PEG-coated liposomes using a continuous supercritical assisted process. J. Supercrit. Fluids 2021, 167, 105048. [CrossRef]

19. Trucillo, P.; Ferrari, P.; Campardelli, R.; Reverchon, E.; Perego, P. A supercritical assisted process for the production of amoxicillinloaded liposomes for antimicrobial applications. J. Supercrit. Fluids 2020, 163, 104842. [CrossRef]

20. Trucillo, P.; Campardelli, R.; Reverchon, E. A versatile supercritical assisted process for the one-shot production of liposomes. J. Supercrit. Fluids 2019, 146, 136-143. [CrossRef]

21. Campardelli, R.; Trucillo, P.; Reverchon, E. A Supercritical Fluid-Based Process for the Production of Fluorescein-Loaded Liposomes. Ind. Eng. Chem. Res. 2016, 55, 5359-5365. [CrossRef]

22. Ciaglia, E.; Montella, F.; Trucillo, P.; Ciardulli, M.; Di Pietro, P.; Amodio, G.; Remondelli, P.; Vecchione, C.; Reverchon, E.; Maffulli, N.; et al. A bioavailability study on microbeads and nanoliposomes fabricated by dense carbon dioxide technologies using human-primary monocytes and flow cytometry assay. Int. J. Pharm. 2019, 570, 118686. [CrossRef] 
23. Steiner, B.M.; McClements, D.J.; Davidov-Pardo, G. Encapsulation systems for lutein: A review. Trends Food Sci. Technol. 2018, 82, 71-81. [CrossRef]

24. Manayi, A.; Abdollahi, M.; Raman, T.; Nabavi, S.M.; Habtemariam, S.; Daglia, M. Lutein and cataract: From bench to bedside. Crit. Rev. Biotechnol. 2015, 36, 829-839. [CrossRef]

25. Chung, R.W.; Leanderson, P.; Lundberg, A.K.; Jonasson, L. Lutein exerts anti-inflammatory effects in patients with coronary artery disease. Atherosclerosis 2017, 262, 87-93. [CrossRef]

26. Maia, M.; Furlani, B.A.; Souza-Lima, A.A.; Martins, D.S.; Navarro, R.M.; Belfort, R. LUTEIN. Retina 2014, 34, 262-272. [CrossRef]

27. Tan, C.; Xia, S.; Xue, J.; Xie, J.; Feng, B.; Zhang, X. Liposomes as Vehicles for Lutein: Preparation, Stability, Liposomal Membrane Dynamics, and Structure. J. Agric. Food Chem. 2013, 61, 8175-8184. [CrossRef]

28. Xia, S.; Tan, C.; Zhang, Y.; Abbas, S.; Feng, B.; Zhang, X.; Qin, F. Modulating effect of lipid bilayer-carotenoid interactions on the property of liposome encapsulation. Colloids Surf. B Biointerfaces 2015, 128, 172-180. [CrossRef]

29. Xia, F.; Hu, D.; Jin, H.; Zhao, Y.; Liang, J. Preparation of lutein proliposomes by supercritical anti-solvent technique. Food Hydrocoll. 2012, 26, 456-463. [CrossRef]

30. Agarwal, S.; Rao, A.V. Carotenoids and Chronic Diseases. Drug Metab. Drug Interact. 2000, 17, 189-210. [CrossRef] [PubMed]

31. Dos Santos, P.P.; Andrade, L.D.A.; Flores, S.; Rios, A.D.O. Nanoencapsulation of carotenoids: A focus on different delivery systems and evaluation parameters. J. Food Sci. Technol. 2018, 55, 3851-3860. [CrossRef] [PubMed]

32. Nagao, A. Absorption and Function of Dietary Carotenoids. Nutr. Cardiovasc. Dis. 2009, 61, 55-63.

33. Tan, C.; Zhang, Y.; Abbas, S.; Feng, B.; Zhang, X.; Xia, S. Modulation of the carotenoid bioaccessibility through liposomal encapsulation. Colloids Surf. B Biointerfaces 2014, 123, 692-700. [CrossRef]

34. Zhao, L.; Temelli, F.; Curtis, J.M.; Chen, L. Encapsulation of lutein in liposomes using supercritical carbon dioxide. Food Res. Int. 2017, 100, 168-179. [CrossRef] [PubMed]

35. Campardelli, R.; Trucillo, P.; Reverchon, E. Supercritical assisted process for the efficient production of liposomes containing antibiotics for ocular delivery. J. $\mathrm{CO}_{2}$ Util. 2018, 25, 235-241. [CrossRef]

36. Singh, P.; Bodycomb, J.; Travers, B.; Tatarkiewicz, K.; Travers, S.; Matyas, G.R.; Beck, Z. Particle size analyses of polydisperse liposome formulations with a novel multispectral advanced nanoparticle tracking technology. Int. J. Pharm. 2019, 566, 680-686. [CrossRef] [PubMed]

37. Junghans, A.; Sies, H.; Stahl, W. Macular Pigments Lutein and Zeaxanthin as Blue Light Filters Studied in Liposomes. Arch. Biochem. Biophys. 2001, 391, 160-164. [CrossRef]

38. Chakravarty, K.; Dalal, D. Mathematical modelling of liposomal drug release to tumour. Math. Biosci. 2018, 306, 82-96. [CrossRef]

39. Patel, G.P.; Crank, C.W.; Leikin, J.B. An Evaluation of Hepatotoxicity and Nephrotoxicity of Liposomal Amphotericin B (L-AMB). J. Med. Toxicol. 2010, 7, 12-15. [CrossRef]

40. Jain, A.; Jain, S.K. In vitro release kinetics model fitting of liposomes: An insight. Chem. Phys. Lipids 2016, 201, 28-40. [CrossRef] [PubMed]

41. Bozzuto, G.; Molinari, A. Liposomes as nanomedical devices. Int. J. Nanomed. 2015, 10, 975-999. [CrossRef] [PubMed]

42. Rodrigues, A.R.O.; Gomes, I.; Almeida, B.G.; de Araújo, J.P.E.; Castanheira, E.M.S.; Coutinho, P.J.G. Magnetic liposomes based on nickel ferrite nanoparticles for biomedical applications. Phys. Chem. Chem. Phys. 2015, 17, 18011-18021. [CrossRef] [PubMed]

43. Qv, X.-Y.; Zeng, Z.-P.; Jiang, J.-G. Preparation of lutein microencapsulation by complex coacervation method and its physicochemical properties and stability. Food Hydrocoll. 2011, 25, 1596-1603. [CrossRef]

44. Abdel-Aal, E.-S.M.; Rabalski, I. Composition of Lutein Ester Regioisomers in Marigold Flower, Dietary Supplement, and Herbal Tea. J. Agric. Food Chem. 2015, 63, 9740-9746. [CrossRef]

45. Becerra, M.O.; Contreras, L.M.; Lo, M.H.; Díaz, J.M.; Herrera, G.C. Lutein as a functional food ingredient: Stability and bioavailability. J. Funct. Foods 2020, 66, 103771. [CrossRef]

46. Sawant, R.R.; Torchilin, V.P. Liposomes as 'smart' pharmaceutical nanocarriers. Soft Matter 2010, 6, 4026-4044. [CrossRef]

47. Kono, K.; Hayashi, H.; Takagishi, T. Temperature-sensitive liposomes: Liposomes bearing poly ( $N$-isopropylacrylamide). $J$. Control. Release 1994, 30, 69-75. [CrossRef]

48. Yuba, E. Development of functional liposomes by modification of stimuli-responsive materials and their biomedical applications. J. Mater. Chem. B 2020, 8, 1093-1107. [CrossRef] [PubMed]

49. Huang, Z.; Li, X.; Zhang, T.; Song, Y.; She, Z.; Li, J.; Deng, Y. Progress involving new techniques for liposome preparation. Asian J. Pharm. Sci. 2014, 9, 176-182. [CrossRef]

50. Lu, T.; Hagen, T.L.T. A novel kinetic model to describe the ultra-fast triggered release of thermosensitive liposomal drug delivery systems. J. Control. Release 2020, 324, 669-678. [CrossRef]

51. Papadopoulou, V.; Kosmidis, K.; Vlachou, M.; Macheras, P. On the use of the Weibull function for the discernment of drug release mechanisms. Int. J. Pharm. 2006, 309, 44-50. [CrossRef] [PubMed]

52. Kosmidis, K.; Argyrakis, P.; Macheras, P. A Reappraisal of Drug Release Laws Using Monte Carlo Simulations: The Prevalence of the Weibull Function. Pharm. Res. 2003, 20, 988-995. [CrossRef] [PubMed]

53. Liu, J.; Conboy, J.C. Direct Measurement of the Transbilayer Movement of Phospholipids by Sum-Frequency Vibrational Spectroscopy. J. Am. Chem. Soc. 2004, 126, 8376-8377. [CrossRef] [PubMed]

54. Koynova, R.; Caffrey, M. Phases and phase transitions of the phosphatidylcholines. Biochim. Biophys. Acta 1998, 1376, 91-145. [CrossRef] 
55. Wang, J.; Ayano, E.; Maitani, Y.; Kanazawa, H. Tunable Surface Properties of Temperature-Responsive Polymer-Modified Liposomes Induce Faster Cellular Uptake. ACS Omega 2017, 2, 316-325. [CrossRef]

56. Zhan, W.; Gedroyc, W.; Xu, X.Y. Towards a multiphysics modelling framework for thermosensitive liposomal drug delivery to solid tumour combined with focused ultrasound hyperthermia. Biophys. Rep. 2019, 5, 43-59. [CrossRef] 